\title{
Effect of Angiotensin-Converting Enzyme Inhibitors and/or Angiotensin Receptor Blockers on the Prevention of Death in Patients with Type 2 Diabetes and Undetermined Nephropathy : Five-Year Survival Data
}

\author{
Sirima Mongkolsomlit ${ }^{1}$, Petch Rawdaree ${ }^{2}$, Chulalux Komoltri ${ }^{3}$, Chamaiporn Tawichasri ${ }^{1}$ and Jayanton Patumanond ${ }^{1 *}$
}

${ }^{1}$ Department of Community Medicine, Faculty of Medicine, Chiang Mai University, Chiang Mai, Thailand

${ }^{2}$ Department of Medicine, Bangkok Metropolitan Medical College and Vajira Hospital, Bangkok, Thailand

${ }^{3}$ Department of Clinical Epidemiology, Faculty of Medicine, Siriraj Hospital, Bangkok, Thailand

\begin{abstract}
Background: Angiotensin-Converting Enzyme Inhibitors (ACEIs) and Angiotensin Receptor Blockers (ARBs) are popular first-line agents for delaying the onset of diabetic nephropathy and diabetic kidney disease in diabetic patients without nephropathy and for reducing all causes of mortality in diabetic patients with nephropathy. However, long-term data showing a reduction in mortality from all causes or renal failure in type 2 diabetes patients with undetermined nephropathy taking ACEIs/ARBs are not available.
\end{abstract}

Objective: To compare renal and other causes of death between those treated and not treated with ACEIs/ARBs in type 2 diabetes patients who are non-nephropathic, nephropathic and have an undetermined nephropathy status.

Methods: Type 2 diabetes patients $(n=7,946)$ who registered with the Thailand Diabetes Registry Project (TDRP) in 2003 were followed-up prospectively for 5 years until January 25, 2008. Baseline demographic data and diabetic nephropathy status were recorded when the patient registered in the TDRP. Living statuses were retrieved from the database of each study site and causes of death were retrieved from the death certificates from the Bureau of Registration Administration of Thailand.

Results: There were 716 type 2 diabetic patients that died within 5 years of registration in the TPDR from all causes of death. Of these cases, 66 died from renal causes. The mortality incidence from renal causes in undetermined nephropathy patients who were treated and not treated with ACEIs/ARBs was 1.25 and 1.30 per 1000 person-years, respectively. After controlling for the propensity score, the competing risk analysis showed that treatment with ACEls/ ARBs was not significantly associated with prevention of death from renal or other causes in type 2 diabetes patients with an undetermined nephropathy status $(\mathrm{HR}=0.83,95 \% \mathrm{Cl}: 0.33-2.09$, $\mathrm{p}$-value $=0.688$ for renal causes; $\mathrm{HR}=1.26$ $95 \% \mathrm{Cl}: 0.97-1.63, \mathrm{p}$-value $=0.085$ for other causes). Treatment with ACEls/ARBs was significantly associated with the prevention of renal and other causes of death in type 2 diabetes patients with nephropathy $(\mathrm{HR}=0.49,95 \% \mathrm{Cl}$ : 0.25 $0.95, \mathrm{p}$-value $=0.034$ for renal causes; $\mathrm{HR}=0.73,95 \% \mathrm{Cl}: 0.56-0.95, \mathrm{p}$-value $=0.019$ for other causes) .

Conclusions: Treatment with ACEls or ARBs is not necessary for everyone, especially in type 2 diabetes patients with an undetermined nephropathy status. Healthcare services teams should screen for microalbuminuria before the treatment of all newly diagnosed type 2 diabetes patients with ACEIs or ARBs.

Keywords: Microalbuminuria; Nephropathy; Angiotensinconverting enzyme; Angiotensin receptor blockers; Survival analysis; Type 2 diabetes

\section{Introduction}

Angiotensin-converting enzyme inhibitors (ACEIs) and angiotensin receptor blockers (ARBs) are popular first-line agents for delaying the onset of diabetic nephropathy and diabetic kidney disease because they are effective in reducing microalbuminuria [14]. The American Diabetes Association (ADA) recommends that for the treatment of non-pregnant patients with microalbuminuria, either ACEIs or ARBs should be prescribed [5]. A previous study has suggested that all middle-aged patients who meet the older diagnostic criteria for diabetes (glucose level $\geq 7.8 \mathrm{mmol} / \mathrm{L}$ ) should receive ACEIs because it is a more cost-effective strategy in the diabetes population to give all middle-aged patients ACEIs than to screen for microalbuminuria [6]. A meta-analysis showed that ACEI treatment reduced all causes of mortality more than treatment with placebo and slowed progression from micro to macroalbuminuria $[7,8]$. However, long-term data showing a reduction in mortality from renal failure or all other causes in type 2 diabetes patients with an undetermined nephropathy status taking ACEIs/ARBs are not available. To fill this important gap in the current knowledge, we performed a retrospective cohort study comparing the five-year mortality incidence to evaluate the effect of treatment with ACEIs/ARBs within the groups of different nephropathy statuses on the prevention of death in type 2 diabetes patients registered by Thailand Diabetes Registry Project (TDRP).

\section{Methods}

\section{Study design and study population}

For this retrospective cohort study, we included type 2 diabetes

*Corresponding author: Jayanton Patumanond, Department of Community Medicine, Faculty of Medicine, Chiang Mai University, Chiang Mai, 50200, Thailand Tel: (66)053-946306; Fax: (66)053-945476; E-mail: jayantorn.s@gmail.com

Received March 24, 2012; Accepted April 17, 2012; Published April 23, 2012

Citation: Mongkolsomlit S, Rawdaree P, Komoltri C, Tawichasri C, Patumanond $J$ (2012) Effect of Angiotensin-Converting Enzyme Inhibitors and/or Angiotensin Receptor Blockers on the Prevention of Death in Patients with Type 2 Diabetes and Undetermined Nephropathy : Five-Year Survival Data. J Diabetes Metab 3:188 doi:10.4172/2155-6156.1000188

Copyright: (C) 2012 Mongkolsomlit S, et al. This is an open-access article distributed under the terms of the Creative Commons Attribution License, which permits unrestricted use, distribution, and reproduction in any medium, provided the original author and source are credited. 
Citation: Mongkolsomlit S, Rawdaree P, Komoltri C, Tawichasri C, Patumanond J (2012) Effect of Angiotensin-Converting Enzyme Inhibitors and/ or Angiotensin Receptor Blockers on the Prevention of Death in Patients with Type 2 Diabetes and Undetermined Nephropathy : Five-Year Survival Data. J Diabetes Metab 3:188. doi:10.4172/2155-6156.1000188

Page 2 of 6

patients in the Thailand Diabetes Registry Project who were eighteen years or older and had no history of renal replacement or dialysis. This multi-center, hospital-based project was carried out from eleven tertiary care centers in university and regional hospitals across Thailand with one private hospital participating in the project.

Our study was conducted only in the ten tertiary care centers in the university and regional hospitals and included 7,946 type 2 diabetes patients who were classified by their nephropathy status. The patients were followed from their registration date until January 25, 2008, and the study endpoint was five-year mortality. The subjects were separated into three groups, non-nephropathic, nephropathic and undetermined nephropathy status, as shown in Figure 1. The study was approved by the ethical committees at each of the hospitals.

\section{Data measurements}

The baseline characteristics measured at registration were demographic data, clinical status of diabetes, diabetic complications and specific medication. These variables were retrieved from the Diabetes Registry Project's database for 2003.

The demographic data and clinical status of the diabetes patients were determined by interviewing and examining the patients. The measurement of diabetic complications was based on clinical diagnoses documented in medical records [9]. Microalbuminuria status was defined by a urine albumin to creatinine ratio above or equal to $3.5 \mathrm{mg} /$ mmol or dipstick with proteinuria or creatinine levels greater than or equal to $152.52 \mu \mathrm{mol} / \mathrm{L}$ [10]. Patients with nephropathy were defined by the presence of at least two out of the three criteria for positive microalbuminuria. Patients without nephropathy were defined by the presence of at least two out of the three criteria for negative microalbuminuria. The subjects who did not have completed laboratory measurements were defined as the undetermined nephropathy group. The laboratory measurements were performed at each site [11].

Treatment with ACEIs or ARBs and other specific treatments were reviewed from the medical records by nurses and verified by clinicians. Specific treatment was classified into 3 groups. First, the antihyperglycemic drug group was defined by the use of sulfonylurea, glinide, metformin, thiazolidinedione and/or alpha-glucosidase inhibitors. Second, the antihypertensive drug group was defined by the use of beta-blockers, alpha-blockers, calcium channel blockers and/or diuretics. Third, the antidyslipidemia drug group was defined by the use of statins and/or fibrates.

Outcome measures were the vital status and the cause of death. The vital status was determined from each hospital's database. For the vital status of patients who lost to follow up was determined from the Bureau of Registration Administration of Thailand's database. The cause of death was determined by examining the death certificate from the Bureau of Registration Administration of Thailand. For each patient, the study had two possible outcomes: a renal cause of death or another cause of death. The other causes of death were cerebrovascular disease, cardiovascular disease, infection, diabetes, cancer and/or suicide.

\section{Statistical analysis}

Descriptive statistics such as the frequency, percentage, mean and standard deviation were used to describe the study subjects. The logrank test was used to compare the differences in cumulative survival for the various treatment groups. Logistic regression was used to calculate the propensity score, which evaluates confounding by indication. The propensity score was calculated by the age, sex, duration of diabetes, systolic blood pressure, diastolic blood pressure, $\mathrm{HbA1C}$ level, total cholesterol level, triglyceride level, high density lipoprotein level, low density lipoprotein level, blood creatinine level, history of ischemic heart disease, smoking, alcohol consumption and the use of insulin or antihyperglycemic, antihypertensive or antidyslipidemic drugs. We utilized the propensity score in the model to adjust for differences between the treatment groups. A Cox proportional hazards model was used to assess the impact of treatment with ACEIs/ARBs on patient mortality from all causes of death after adjusting for the propensity score.

A competing risk model was used to assess the impact of treatment with ACEIs/ARBs on patient mortality from renal failure and other causes of death. The reported probability values were two-sided. All statistical analyses were performed with STATA software version 11.0.

\section{Results}

\section{Characteristics at registration}

The baseline characteristics of 7,946 type 2 diabetes patients at registration, classified by nephropathy history and ACEI/ARBs used, are shown in Table 1. The percentages of non-nephropathic, nephropathic and undetermined nephropathy status subjects were $23.2 \%, 33.1 \%$ and $43.7 \%$, respectively. The diabetes patients without nephropathy who were treated with ACEIs/ARBs had been diagnosed with diabetes for longer, a higher body mass index, a higher blood pressure and a more frequent history of hypertension than patients not prescribed ACEI/ARBs. For diabetes patients with nephropathy, those treated with ACEI/ARBs had lower creatinine levels than the patients not prescribed ACEI/ARBs. In diabetes patients with undetermined nephropathy, those treated with ACEIs/ARBs had similar characteristics to the diabetes patients without nephropathy. We then calculated the propensity score to determine confounding by indication. The propensity scores in subjects treated with ACEIs/ARBs for all nephropathy status groups were higher than for those patients who were not prescribed ACEIs/ARBs.

\section{Survival time before death}

Within 5 years, 716 patients died from various causes. In nonnephropathic, nephropathic and undetermined nephropathy status patients treated with ACEI/ARBs, there were 35 deaths from 5181.1



Figure 1: Patient exclusion criteria and classification. 
Citation: Mongkolsomlit S, Rawdaree P, Komoltri C, Tawichasri C, Patumanond J (2012) Effect of Angiotensin-Converting Enzyme Inhibitors and/ or Angiotensin Receptor Blockers on the Prevention of Death in Patients with Type 2 Diabetes and Undetermined Nephropathy : Five-Year Survival Data. J Diabetes Metab 3:188. doi:10.4172/2155-6156.1000188

Page 3 of 6

person-years of total follow-up, 152 deaths from 5062.4 person-years of total follow-up and 140 deaths from 6388.2 person-years of total follow-up, respectively. For subjects not treated with ACEIs/ARBs, in the non-nephropathic, nephropathic and undetermined nephropathy status patients there were 73 deaths from 7,536.9 person-years of total follow-up, 141 deaths from 3,226.7 person-years of total follow-up and 175 deaths from 100001.7 person-years of total follow-up, respectively. There were 66 patients who died from causes of renal failure and 650 who died of other causes. The incidence mortality from renal causes and other causes, grouped according to nephropathy history and ACEIs/ARBs treatment status, are displayed in Table 2.

When the cumulative hazards function for death from renal failure was compared between those treated with or without ACEIs/ARBs in non-nephropathic, nephropathic and undetermined nephropathy status subjects, there were statistically significant differences between the groups only in nephropathic subjects $(p=0.034)$. In regards to the cumulative hazards function for death from other causes between those treated with or without ACEIs/ARBs in non-nephropathic, nephropathic and undetermined nephropathy status subjects, there were statistically significant differences between the groups in the nephropathic group $(p=0.019)$ and the not nephropathic group $(p=$ 0.018). However, in undetermined nephropathy subjects, there was no statistically significant difference between those treated with or without ACEIs/ARBs $(p=0.085)$ as displayed in Figure 2.

\section{Role of ACEIs/ARBs in death from all causes}

In the univariate Cox model, treatment with ACEIs/ARBs was associated with all causes of death in the non-nephropathic, nephropathic and the undetermined nephropathy status groups with the respective crude hazard ratios 0.70 (95\% CI $0.47-1.04 ; p=0.081)$ 0.68 (95\% CI $0.55-0.87 ; p=0.001)$ and $1.25(95 \%$ CI $1.01-1.56 ; p=$

\begin{tabular}{|c|c|c|c|c|c|c|}
\hline \multirow[b]{2}{*}{ Baseline characteristics } & \multicolumn{2}{|c|}{ No Nephropathy } & \multicolumn{2}{|c|}{ Nephropathy } & \multicolumn{2}{|c|}{ Undetermined } \\
\hline & $\begin{array}{c}\text { ACEIs/ARBs } \\
(n=1,070)\end{array}$ & $\begin{array}{c}\text { No ACEIs/ARBs } \\
(n=1,557)\end{array}$ & $\begin{array}{c}\text { ACEIs/ARBs } \\
(n=1,106)\end{array}$ & $\begin{array}{c}\text { No ACEIs/ARBs } \\
(n=740)\end{array}$ & $\begin{array}{c}\text { ACEIs/ARBs } \\
(n=1,365)\end{array}$ & $\begin{array}{c}\text { No ACEIs/ARBs } \\
(n=2,108)\end{array}$ \\
\hline Male & $380(35.5)$ & $464(29.8)$ & $460(41.6)$ & $244(33.0)$ & $398(29.2)$ & $601(28.5)$ \\
\hline Age, (year) & $61.8 \pm 10.2$ & $59.2 \pm 11.5$ & $62.4 \pm 10.6$ & $62.1 \pm 12.0$ & $62.4 \pm 10.4$ & $59.6 \pm 11.8$ \\
\hline Duration of DM, (year) & $10.1 \pm 7.2$ & $9.1 \pm 7.4$ & $12.1 \pm 8.1$ & $11.9 \pm 8.3$ & $10.7 \pm 7.2$ & $9.1 \pm 7.1$ \\
\hline Onset of DM, (year) & $51.7 \pm 10.9$ & $50.1 \pm 11.1$ & $50.3 \pm 11.3$ & $50.2 \pm 12.1$ & $51.6 \pm 10.5$ & $50.4 \pm 11.3$ \\
\hline Body mass index, $\left(\mathrm{kg} / \mathrm{m}^{2}\right)$ & $26.0 \pm 3.9$ & $25.2 \pm 4.1$ & $26.0 \pm 4.4$ & $25.8 \pm 4.7$ & $26.1 \pm 4.5$ & $25.4 \pm 4.3$ \\
\hline Systolic blood pressure, $(\mathrm{mmHg})$ & $145.1 \pm 21.3$ & $137.0 \pm 19.9$ & $150.3 \pm 24.7$ & $147.1 \pm 24.8$ & $146.9 \pm 21.6$ & $138.1 \pm 19.9$ \\
\hline Diastolic blood pressure, $(\mathrm{mmHg})$ & $79.0 \pm 11.2$ & $77.0 \pm 10.7$ & $79.4 \pm 12.6$ & $77.4 \pm 11.6$ & $80.6 \pm 10.8$ & $79.0 \pm 10.3$ \\
\hline $\mathrm{HbA} 1 \mathrm{C},(\%)$ & $7.9 \pm 1.7$ & $7.9 \pm 1.7$ & $8.5 \pm 2.1$ & $8.4 \pm 2.0$ & $8.2 \pm 1.8$ & $8.2 \pm 1.9$ \\
\hline Cholesterol, (mmol/L) & $4.9 \pm 0.9$ & $5.0 \pm 1.0$ & $5.1 \pm 1.2$ & $5.3 \pm 1.4$ & $5.2 \pm 1.1$ & $5.2 \pm 1.1$ \\
\hline Triglyceride, (mmol/L) & $1.6 \pm 0.9$ & $1.5 \pm 0.9$ & $1.9 \pm 1.6$ & $2.0 \pm 1.6$ & $1.8 \pm 1.0$ & $1.8 \pm 1.3$ \\
\hline High density lipoprotein, (mmol/L) & $1.4 \pm 0.4$ & $1.3 \pm 0.4$ & $1.3 \pm 0.4$ & $1.3 \pm 0.3$ & $1.4 \pm 0.4$ & $1.3 \pm 0.4$ \\
\hline Low density lipoprotein, (mmol/L) & $2.8 \pm 0.8$ & $2.9 \pm 0.8$ & $3.0 \pm 1.0$ & $3.0 \pm 1.1$ & $3.1 \pm 0.9$ & $3.0 \pm 0.9$ \\
\hline Creatinine, $(\mu \mathrm{mol} / \mathrm{L})$ & $89.5 \pm 44.7$ & $86.9 \pm 100.5$ & $121.2 \pm 68.2$ & $152.8 \pm 121.9$ & $103.1 \pm 44.8$ & $96.4 \pm 41.0$ \\
\hline Ischemic heart disease & $88(8.3)$ & $89(5.7)$ & $119(10.8)$ & $80(10.9)$ & $147(10.9)$ & $148(7.1)$ \\
\hline History of dyslipidemia & $874(81.7)$ & $1,130(72.6)$ & $876(79.2)$ & $563(76.1)$ & $1,023(74.9)$ & $1,386(65.8)$ \\
\hline History of hypertension & $991(92.6)$ & $609(39.1)$ & $984(89.0)$ & $530(71.6)$ & $1,275(93.4)$ & $939(44.5)$ \\
\hline Smoking & $200(18.7)$ & $276(17.7)$ & $303(27.4)$ & $165(22.3)$ & $234(17.1)$ & $376(17.8)$ \\
\hline Alcohol drinking & $195(18.2)$ & $245(15.7)$ & $260(23.5)$ & $143(19.3)$ & $242(17.7)$ & $412(19.5)$ \\
\hline Use of insulin & $221(20.7)$ & $300(19.3)$ & $393(35.5)$ & $310(41.9)$ & $325(23.8)$ & $461(21.9)$ \\
\hline Use of antihyperglycemic drugs & $999(93.4)$ & $1,246(91.4)$ & $941(85.1)$ & $522(70.5)$ & $1,246(91.3)$ & 1,891 (89.7) \\
\hline Use of antihypertensive drugs & $573(53.6)$ & $484(31.1)$ & $656(59.3)$ & $478(64.6)$ & $818(59.9)$ & $794(37.7)$ \\
\hline Use of antidyslipidemic drugs & $712(66.5)$ & $895(57.5)$ & $708(64.0)$ & $442(59.7)$ & $746(54.7)$ & $917(43.5)$ \\
\hline Propensity score & $0.50 \pm 0.12$ & $0.42 \pm 0.12$ & $0.51 \pm 0.14$ & $0.48 \pm 0.14$ & $0.47 \pm 0.13$ & $0.40 \pm 0.13$ \\
\hline
\end{tabular}

Numbers are $\mathrm{n}(\%)$ or mean \pm standard deviation (SD)

Table 1: Baseline characteristics of patients prescribed $(n=3,541)$ or not prescribed $(n=4,405)$ ACEls/ARBs, classified by nephropathy status at registration.

\begin{tabular}{|c|c|c|c|c|c|c|}
\hline \multirow[b]{2}{*}{ Outcome parameters } & \multicolumn{2}{|c|}{ No Nephropathy } & \multicolumn{2}{|c|}{ Nephropathy } & \multicolumn{2}{|c|}{ Undetermined } \\
\hline & $\begin{array}{c}\text { ACEIs/ARBs } \\
(n=1,070)\end{array}$ & $\begin{array}{c}\text { No ACEIs/ARBs } \\
(n=1,557)\end{array}$ & $\begin{array}{c}\text { ACEIs/ARBs } \\
(n=1,106)\end{array}$ & $\begin{array}{c}\text { No ACEIs/ARBs } \\
(n=740)\end{array}$ & $\begin{array}{c}\text { ACEIs/ARBs } \\
(n=1,365)\end{array}$ & $\begin{array}{c}\text { No ACEIs/ARBs } \\
(n=2,108)\end{array}$ \\
\hline Total follow-up time (year) & 5181.1 & 7536.9 & 5062.4 & 3226.7 & 6388.2 & 10001.7 \\
\hline Mean follow-up time (year) & $4.84 \pm 0.73$ & $4.84 \pm 0.72$ & $4.58 \pm 1.12$ & $4.36 \pm 1.36$ & $4.68 \pm 0.99$ & $4.74 \pm 0.89$ \\
\hline \multicolumn{7}{|l|}{ Death from renal causes } \\
\hline Number $(n=66)$ & 3 & 1 & 18 & 23 & 8 & 13 \\
\hline Incidence (per 1,000 person-years) & 0.58 & 0.13 & 3.56 & 7.13 & 1.25 & 1.30 \\
\hline \multicolumn{7}{|l|}{ Death from other causes } \\
\hline Number $(n=650)$ & 32 & 72 & 134 & 118 & 132 & 162 \\
\hline Incidence (per 1,000 person-years) & 6.18 & 9.55 & 26.47 & 36.57 & 20.66 & 16.20 \\
\hline \multicolumn{7}{|l|}{ Death from all causes } \\
\hline Number $(n=716)$ & 35 & 73 & 152 & 141 & 140 & 175 \\
\hline Incidence (per 1,000 person-years) & 6.76 & 9.69 & 30.03 & 43.70 & 21.92 & 17.50 \\
\hline
\end{tabular}

Table 2: Follow-up time and survival time in patients prescribed $(n=3,541)$ and not prescribed $(n=4,405)$ ACEls/ARBs, classified by nephropathy status at registration. 
Citation: Mongkolsomlit S, Rawdaree P, Komoltri C, Tawichasri C, Patumanond J (2012) Effect of Angiotensin-Converting Enzyme Inhibitors and/ or Angiotensin Receptor Blockers on the Prevention of Death in Patients with Type 2 Diabetes and Undetermined Nephropathy : Five-Year Survival Data. J Diabetes Metab 3:188. doi:10.4172/2155-6156.1000188
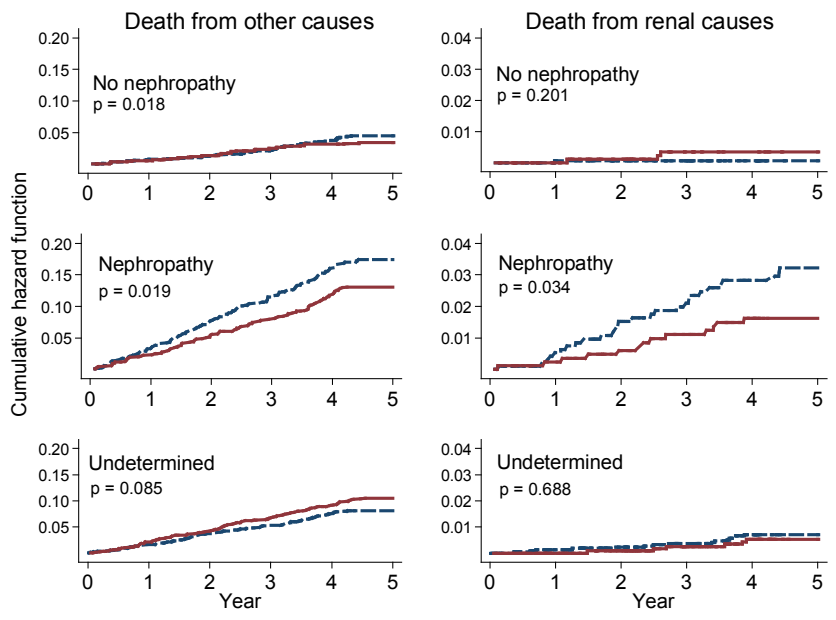

Figure 2: Five year cumulative hazard function of deaths from other causes and deaths from renal failure for patients classified by nephropathy history, solid line (with ACEIs/ARBs) and dash line (without ACEIs/ARBs).

0.048). Hazard ratios for death after adjusting for the propensity score in non-nephropathic, nephropathic and undetermined nephropathy status groups were 0.65 (95\% CI $0.42-1.00 ; p=0.049)$ ), 0.69 (95\% CI $0.54-0.88 ; p=0.003)$ and $1.22(95 \%$ CI $0.95-1.56 ; p=0.122)$, as shown in Table 3.

\section{Role of treatment with ACEIs/ARBs in deaths from renal failure}

In the competing risk model, we examined the relationship between treatment with ACEIs/ARBs and death from renal failure in the nonnephropathic, nephropathic and undetermined nephropathy status groups as displayed in Table 3. Crude hazard ratios were $4.38(95 \%$ CI $0.46-42.07 ; p=0.201), 0.50$ (95\% CI $0.27-0.3 p=0.027)$ and 0.97 (95\% CI $0.40-2.23 ; p=0.938$ ) for the non-nephropathic, nephropathic, and undetermined nephropathy status groups, respectively. After controlling for the propensity score, treatment with ACEIs/ARBs was associated with prevented deaths from renal failure in the group of patients with nephropathy (HR $=0.49,95 \%$ CI: $0.25-0.95, p=$ $0.034)$. The adjusted hazard ratio for death from renal failure in the undetermined nephropathy patients was 0.83 (95\% CI: 0.33-2.09, $\mathrm{p}$-value $=0.688$ ). The adjusted hazard ratio for death from renal failure in the non nephropathic group could not be calculated due to too small a number of events.

\section{Role of treatment with ACEIs/ARBs in deaths from non- renal causes}

The crude hazard ratio result showed that deaths from other causes were significantly different between those treated with or without ACEI/ ARBs in all nephropathy status groups $(\mathrm{P}<0.05)$. After controlling for the propensity scores in the competing risk model, the occurrence of other causes of death was significantly altered by treatment with ACEIs/ARBs in non nephropathic and nephropathic patient groups with the respective hazard ratios of 0.65 (95\% CI 0.42-0.99; $p=0.049$ ) and 0.69 (95\% CI 0.54-0.88; $p=0.003$ ). Treatment with ACEIs/ARBs was not associated with the prevention of other causes of death in the undetermined nephropathy status group and had a hazard ratio of 1.22 (95\% CI 0.95-1.56; $p=0.122)$.

\section{Discussion}

This study was a retrospective cohort study. A major issue with this study design is that observational studies are more exposed and prone to biases, especially intention to treat bias, which can partly be addressed through rigorous study design or statistical analysis. Propensity score techniques are the most frequently used method of addressing this problem. The propensity score is the probability that an individual would receive a certain treatment based on his/her treatment characteristics $[12,13]$. The study used propensity scores to achieve a balance among confounders between the treatment groups in the model.

After controlling for the propensity scores in the competing risk model and Cox model to evaluate the effect of treatment with ACEIs/ ARBs on the prevention of renal causes, other causes and all causes of death, treatment with ACEIs/ARBs was associated with the prevention of death from renal causes, other causes and all causes at a level that was significantly different from those not treated with ACEIs/ARBs in diabetes patients with nephropathy. This finding confirms the metaanalysis study that found that treatment with ACEIs/ARBs can reduce renal-cause, other-cause and all-cause mortality in diabetes patients with nephropathy $[14,15]$. Initial studies by Lewis have demonstrated that a slowing of the nephropathy progression rate was reflected in a significant increase in the time until the serum creatinine concentration doubles, which approximates a halving of the glomerular filtration rate [16]; ARBs were effective in reducing the doubling time of creatinine in type 2 diabetics [17]. Treatment with ARBs reduced the pressure against the filter by dilating the blood vessels that take blood away from the filter in the kidney. Usually, diabetes nephropathy patients should be treated with ACEIs/ARBs. However, in our study, approximately $40 \%$ of nephropathy patients did not receive ACEIs/ARBs. There was a systematic review study which reported specific adverse events of ACEIs/ARBs treatment, including coughing, headaches, dizziness, fatigue, upper respiratory infection, nausea, viral infection, ankle edema, back pain, palpitations, myalgia, diarrhea, malaise, and hypotension [18]. Potentially, a large portion of patients in this study were not prescribed ACEIs/ARBs because their doctors forgot to prescribe them or they were known to have a predisposition to the side effects mentioned above.

In type 2 diabetes patients without nephropathy, treatment with ACEIs/ARBs was associated with the prevention of death from other causes and renal causes of death at a level that was significantly different from those not treated with ACEIs/ARBs. This finding fulfills the knowledge gap and shows that the treatment with ACEIs/ARB is beneficial for the prevention of death in diabetes patients without nephropathy. Eurich's study found that the use of ACEIs was associated with a significant reduction in all-cause and cardiovascular-related mortality in a broad spectrum of patients with type 2 diabetes and no cardiovascular disease [19]. Because ACEIs/ARBs work by interfering with the formation of a hormone that can narrow blood vessels and increase blood pressure, they are prescribed to reduce blood pressure and ease the workload on the heart. A previous study suggested that ACE inhibitors may provide special advantages in addition to blood pressure control and may be superior to alternative antihypertensive agents [20].

Our study finds that treatment with ACEIs/ARBs could not prevent mortality from renal causes, other causes and all causes of death in type 2 diabetes patients with an undetermined nephropathy status. There was a trend that patients who received ACEIs/ARBs had more deaths from other causes than patients who did not receive treatment with 
Citation: Mongkolsomlit S, Rawdaree P, Komoltri C, Tawichasri C, Patumanond J (2012) Effect of Angiotensin-Converting Enzyme Inhibitors and/ or Angiotensin Receptor Blockers on the Prevention of Death in Patients with Type 2 Diabetes and Undetermined Nephropathy : Five-Year Survival Data. J Diabetes Metab 3:188. doi:10.4172/2155-6156.1000188

Page 5 of 6

\begin{tabular}{|c|c|c|c|c|c|c|}
\hline & \multicolumn{2}{|c|}{ No Nephropathy } & \multicolumn{2}{|c|}{ Nephropathy } & \multicolumn{2}{|c|}{ Undetermined } \\
\hline & $\mathrm{HR}(95 \% \mathrm{Cl})$ & $p$-value & $\mathrm{HR}(95 \% \mathrm{Cl})$ & $p$-value & $\mathrm{HR}(95 \% \mathrm{Cl})$ & $\mathrm{p}$-value \\
\hline \multicolumn{7}{|c|}{ Death from renal causes } \\
\hline Crude & $4.38(0.46-42.07)$ & 0.201 & $0.50(0.27-0.93)$ & 0.027 & $0.97(0.40-2.33)$ & 0.938 \\
\hline Adjusted for PS ${ }^{a}$ & $\mathrm{NC}{ }^{b}$ & - & $0.49(0.25-0.95)$ & 0.034 & $0.83(0.33-2.09)$ & 0.688 \\
\hline \multicolumn{7}{|c|}{ Death from other causes } \\
\hline Crude & $0.65(0.43-0.98)$ & 0.041 & $0.73(0.57-0.93)$ & 0.011 & $1.27(1.01-1.60)$ & 0.039 \\
\hline Adjusted for PS ${ }^{a}$ & $0.58(0.37-0.91)$ & 0.018 & $0.73(0.56-0.95)$ & 0.019 & $1.26(0.97-1.63)$ & 0.085 \\
\hline \multicolumn{7}{|l|}{ Death from all causes } \\
\hline Crude & $0.70(0.47-1.04)$ & 0.081 & $0.68(0.55-0.87)$ & 0.001 & $1.25(1.01-1.56)$ & 0.048 \\
\hline Adjusted for $\mathrm{PS}^{\mathrm{a}}$ & $0.65(0.42-0.99)$ & 0.049 & $0.69(0.54-0.88)$ & 0.003 & $1.22(0.95-1.56)$ & 0.122 \\
\hline
\end{tabular}

aPS: Propensity Score (age, sex, duration of diabetes, systolic blood pressure, diastolic blood pressure, HbA1C, total cholesterol, triglyceride, high density lipoprotein, low density lipoprotein, creatinine, history of ischemic heart disease, smoking, alcohol drinking, use of insulin, antihyperglycemic drugs, antihypertensive drug and antidyslipidemic drugs)

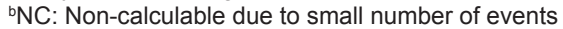

Table 3: Hazard ratio (HR) and 95\% confidence interval $(\mathrm{Cl})$ for death from renal causes, other causes and all causes in patients prescribed with ACEls/ARBs, classified by nephropathy status at registration.

ACEIs/ARBs (HR = 1.26; 95\% CI; 0.97-1.63, p = 0.085). We explored baseline characteristics between the groups separated by nephropathy status (Table 1). The data showed that subjects with an undetermined nephropathy status had a higher diastolic blood pressure level, Hbalc and history of ischemic heart disease than subjects with and without nephropathy. These factors are diabetes control quality indicators. We recommend that the next study explore causes of death related to diabetes control in undetermined nephropathy status patients.

Of the studied subjects in the tertiary hospitals, $43.7 \%$ of type 2 diabetes patients were not screened for microalbuminuria because the screening tools in Thailand are expensive and the method of urine collection is not convenient for patients willing to complete the test necessarily for 3 times. We have estimated from this information that type 2 diabetes patients in a general hospital may not have a determined nephropathy status in more than $80 \%$ of cases. In the future, if there were a simple screening test that was highly predictive and practical to use to detect microalbuminuria, type 2 diabetes patients would obtain more suitable treatment and care.

There are several limitations to this study. First, the World Health Organization (WHO) standard decision rule, in which specific ICD10 codes for the cause of death were identified, should be applied. Our study utilized causes of death from the death certificates from the Bureau of Registration Administration of Thailand. The cause of death in the document can be completed by a health care team or a doctor. However, the outcome event of this study is similar to the outcome event of the project predicting death and causes of death in Thai diabetic patients [21]. The cause of death of diabetic patients in that study was defined by a panel of two independent physicians after reviewing the medical records, and causes of death were categorized according to the International Classification of Disease, Tenth Revision (ICD-10). Cardiovascular disease is the most common cause of death (29.0\%), followed by infection (21.9\%), cancer (19.5\%) and chronic kidney disease (8.6\%). For our study, cardiovascular disease was the most common cause of death (26.7\%), followed by infection $(23.5 \%)$, cancer $(16.2 \%)$ and renal failure (9.3\%).

Second, the laboratory and clinical factors in this study were based on a single baseline measurement at the time of registration without repeated measures during the five years of follow-up. Last, this study did not collect the dosage of administered ACEIs/ARBs. The next study should consider changes in treatment and other variables. However, the strength of this study is in its prospective nature and its large number of type 2 diabetes patients who can represent diabetic patients in a hospital. Moreover, other developing countries have similar diabetes characteristics as Thailand, so the study may be representative of other developing countries.

In conclusion, diabetic nephropathy patients who received ACEIs/ARBs had lower mortality than subjects who did not receive the drugs. The effect on mortality of treatment with ACEIs/ARBs was not statistically significant in subjects who were not diagnosed with diabetic nephropathy. A screening test for diabetic nephropathy should be performed to determine the administration of ACEIs and ARBs.

\section{Acknowledgments}

This project was supported by grants from the Faculty of Medicine Research Fund, Chiang Mai University, Thailand. We would like to thank the Thailand Diabetes Registry Project and the Endocrine Society of Thailand for giving us the opportunity to use their data. The authors declare that there is no conflict of interest associated with this manuscript.

\section{References}

1. Poulsen PL (2003) ACE inhibitor intervention in Type 1 diabetes with low grade microalbuminuria. J Renin Angiotensin Aldosterone Syst 4: 17-26.

2. Bakris GL, Slataper R, Vicknair N, Sadler R (1994) ACE inhibitor mediated reductions in renal size and microalbuminuria in normotensive, diabetic subjects. J Diabetes Complications 8: 2-6.

3. Bakris GL, Smith AC, Richardson DJ, Hung E, Preston R, et al. (2002) Impact of an ACE inhibitor and calcium antagonist on microalbuminuria and lipid subfractions in type 2 diabetes: a randomised, multi-centre pilot study. J Hum Hypertens 16: 185-191.

4. Gross JL, de Azevedo MJ, Silveiro SP, Canani LH, Caramori ML, et al. (2005) Diabetic nephropathy: diagnosis, prevention, and treatment. Diabetes Care 28 164-176.

5. American Diabetes Association (2009) Standards of medical care in diabetes Diabetes Care 32: S13-S61.

6. Golan L, Birkmeyer JD, Welch HG (1999) The cost-effectiveness of treating all patients with Type 2 diabetes with angiotensin-converting enzyme inhibitors. Ann Intern Med 131: 660-667.

7. McFarlane PA (2006) Review: ACE inhibitors delay onset of microalbuminuria in diabetes without nephropathy and reduce mortality in diabetic nephropathy. ACP J Club 145: 35

8. Tomoko T, Shin-ichi Y, Nobunori S, Shiro U (2003) Meta-analysis: Effect of ACE-inhibitors on outcomes in patients with renal insufficiency. P\&T 28: 98112

9. Rawdaree P, Ngarmukos C, Deerochanawong C, Suwanwalaikorn S Chetthakul T, et al. (2006) Thailand Diabetes Registry (TDR) Project: Clinica Status and Long Term Vascular Complications in Diabetic Patients. J Med Assoc Thai 89: S1-S9. 
Citation: Mongkolsomlit S, Rawdaree P, Komoltri C, Tawichasri C, Patumanond J (2012) Effect of Angiotensin-Converting Enzyme Inhibitors and/ or Angiotensin Receptor Blockers on the Prevention of Death in Patients with Type 2 Diabetes and Undetermined Nephropathy : Five-Year Survival Data. J Diabetes Metab 3:188. doi:10.4172/2155-6156.1000188

10. American Diabetes Association (2010) Standards of medical care in diabetes--2010. Diabetes Care 33: S11-S61.

11. Ngarmukos C, Bunnag P, Kosachunhanun N, Krittiyawong S, Leelawatana R et al. (2006) Thailand Diabetes Registry Project: Prevalence, Characteristics and Treatment of Patients with Diabetic Nephropathy. J Med Assoc Thai 89: S37-S42.

12. Belitser SV, Martens EP, Pestman WR, Groenwold RH, de Boer A, et al. (2011) Measuring balance and model selection in propensity score methods. Pharmacoepidemiol Drug Saf 20: 1115-1129.

13. Groenwold RH, de Vries F, de Boer A, Pestman WR, Rutten FH, et al. (2011) Balance measures for propensity score methods: a clinical example on betaagonist use and the risk of myocardial infarction. Pharmacoepidemiol Drug Saf 20: $1130-1137$

14. McFarlane PA (2006) Review: ACE inhibitors delay microalbuminuria in diabetes without nephropathy and reduce mortality in diabetic nephropathy. Evid Based Med 11: 144

15. Eurich DT, Majumdar SR, Tsuyuki RT, Johnson JA (2004) Reduced mortality associated with the use of ACE inhibitors in patients with type 2 diabetes. Diabetes care 27: 1330-1334.
16. Lewis EJ, Hunsicker LG, Bain RP, Rohde RD (1993) The effect of angiotensinconverting-enzyme inhibition on diabetic nephropathy. The Collaborative Study Group. N Engl J Med 329: 1456-1462.

17. Lewis EJ, Hunsicker LG, Clarke WR, Berl T, Pohl MA et al. (2001) Renoprotective effect of the angiotensin-receptor antagonist irbesartan in patients with nephropathy due to type 2 diabetes. N Engl J Med 345: 851-860.

18. Matchar DB, McCrory DC, Orlando LA, Patel MR, Patel UD, et al. (2008) Systematic review: comparative effectiveness of angiotensin-converting enzyme inhibitors and angiotensin II receptor blockers for treating essential hypertension. Ann Intern Med 148:16-29.

19. Eurich DT, Majumdar SR, Tsuyuki RT, Johnson JA (2004) Reduced mortality associated with the use of ACE inhibitors in patients with type 2 diabetes. Diabetes Care 27: 1330-1334.

20. Pahor M, Psaty BM, Alderman MH, Applegate WB, Williamson JD, et al. (2000) Therapeutic benefits of ACE inhibitors and other antihypertensive drugs in patients with type 2 diabetes. Diabetes Care 23: 888-892.

21. Pratipanawatr $T$, Rawdaree $P$, Chetthakul $T$, Bunnag $P$, Ngarmukos $C$, et al. (2010) Thailand Diabetic Registry cohort: predicting death in Thai diabetic patients and causes of death. J Med Assoc Thai 93: S12-S20. 